\title{
CUADERNO DE FILOSOFÍA. DICTADO POR DON ANDRÉS BELLO PARA EL USO DE JUAN ALEMPARTE
}

\author{
Abel Aravena Zamora \\ Centro de Estudios Avanzados, Universidad de Playa Ancha \\ abel.aravena@upla.cl \\ Francisco Cordero Morales \\ Centro de Estudios Históricos, Universidad Bernardo O’Higgins \\ fjcorderomorales@gmail.com
}

Es sabido que a menos de un lustro del arribo de Andrés Bello a Chile (1829), el sabio venezolano -en medio de la ingente cantidad de labores que desarrollaba- comenzó a impartir clases particulares en su domicilio ubicado en el centro de Santiago. Repetía así una actividad que había ejercido en Caracas siendo aún muy joven y, luego, en su estadía en Londres. En efecto, en su tierra natal el futuro jurisconsulto fungió de profesor particular de literatura y geografía de Simón Bolívar, quien era solo dos años menor que su mentor (Jaksic, La pasión 36); mientras que en la capital del Imperio británico hizo las veces de profesor de idiomas e institutor de los hijos de Mr. Hamilton, un alto funcionario del Ministerio de Relaciones Exteriores inglés (68). Como se puede colegir, en dichas ocasiones en que Bello trabajó de profesor privado, sus alumnos provenían de acomodadas 
y distinguidas familias. En la ciudad de Santiago no fue la excepción. De hecho, la totalidad de los jóvenes que asistieron a las lecciones personales del maestro caraqueño se caracterizan por su filiación a la élite nacional de la época, alcanzando varios de ellos fama en la historia de Chile. Miguel Luis Amunátegui, en su clásico libro Vida de Don Andrés Bello, informa sobre los ańos y los cursos privados realizados por el insigne educador, y da a conocer también el nombre de cerca de una treintena de sus alumnos, distinguiéndolos según las lecciones recibidas (232-41).

Siguiendo lo sostenido por Amunátegui (236), el curso de filosofía habría sido el más tardío de los ofrecidos por el pedagogo venezolano en su domicilio ${ }^{1}$, pues en 1831 enseñó derecho natural y de gente ${ }^{2}$; en 1834, sumó latín y derecho romano ${ }^{3}$; y, probablemente, desde 1840 incluyó filosofía (Amunátegui 236).

Aníbal Pinto, Manuel Antonio y Felipe Santiago Matta, Nicomedes Ossa, Javier Rengifo, Santiago Lindsay, Francisco Bilbao, Manuel Valledor, y Juan y Andrés Ricardo Bello Dunn, entre otros, dice Amunátegui (236), se contaron como alumnos de las clases de filosofía de Bello. Pero, que se sepa, y más allá del nombre de estos discípulos, hasta ahora no existe testimonio documental alguno de las materias filosóficas específicas abordadas por el sabio venezolano en dicha clase ${ }^{4}$.

Lo conocido, y respecto de lo que sí hay acuerdo entre los historiógrafos, es que el prestigioso profesor comenzó a difundir sus consideraciones filosóficas -y literarias en general- en 1843 y 1844, en el periódico El Crepúsculo, iniciado por José Victorino Lastarria. Al año siguiente, o sea en 1845, y hasta 1849 , Bello divulga distintos escritos referidos a filosofía, sobre todo

Raúl Silva Castro estima que estos cursos se habrían extendido hasta el año 1843 (49). Según el historiador Julio César Jobet, en 1831 Andrés Bello enseña también Humanidades (158).

3 Sostiene Lastarria, uno de los alumnos de Bello, que en 1834 comenzó a enseñar "en su casa dos cursos, uno de gramática y literatura, y el otro de derecho romano y español” (Feliú 5).

4 Con respecto a la documentación de las materias específicas estudiadas en los albores de la disciplina en Chile, véase la recuperación de obras manuscritas inéditas de Aravena Zamora ("Fuentes filosóficas"; "La enseñanza”; "Sobre unas"; "La Física”). 
en el periódico El Araucano, del cual fue director ${ }^{5}$. Aunque serán solo sus ideas expresadas en El Crepúsculo las que constituirán tiempo después, con ciertas correcciones, la introducción y fragmentos del capítulo 1, sobre las "Las percepciones", de su obra Filosofía del entendimiento $(F d E)$, que se editará en 1881 (Bello 1881).

Según Walter Hanisch, Bello "se demoraba mucho tiempo en publicar [en las revistas de la época] las diversas partes de sus artículos filosóficos" (72), indicio claro de un lento y estudiado proceso de escritura. De esta costumbre del reconocido gramático se puede seguir, sin duda, que el curso privado de filosofía que impartió en su domicilio, por una parte, lo preparó con bastante antelación a las clases mismas y, por otra, le sirven para exponer, conversar y discutir con sus alumnos (Lastarria 77) los temas y contenidos que presenta en formato de artículos en el periódico El Crepúsculo. Es decir que, las lecciones de filosofía del consejero de gobierno, en lo relativo a su preparación, enseñanza y casi a la par publicación, habrían tenido un proceso poco más o menos similar al de sus otras lecciones ${ }^{6}$.

Ahora bien, y conforme a lo señalado, tanto el nombre de Juan Alemparte en cuanto alumno de las clases privadas de filosofía de Bello, como su inédito manuscrito Cuaderno de filosofía, representan una completa rareza y novedad. Pues, si bien Alemparte sería uno de esos otros alumnos que sostiene Amunátegui recibió instrucción del sabio venezolano en filosofía, solo Iván Jaksic los vincularía ${ }^{7}$. Sin embargo, en la actualidad su olvidado

Según Amunátegui (430), en el periódico El Araucano Bello dio a conocer sus "doctrinas de psicología y lógica al juzgar el Curso de filosofía moderna, por don Ramón Briceño" (marzo, 1845); su "Apuntes sobre la teoría de los sentimientos morales de Mr. Jouffroy" (noviembre y diciembre, 1846; junio, 1847); y "La filosofía fundamental por el presbítero don Jaime Balmes” (marzo, 1848). También en la Revista de Santiago, Bello insertó el "Curso completo de filosofía por Mr. Rattier" (julio y agosto, 1848; marzo, 1849).

6 Un año después de que Bello comenzara a impartir sus clases privadas de derecho, publica Principios de derecho internacional y Principios de derecho de gentes (1832); y un ańo después de que iniciara su enseñanza del latín, hace público su texto Lecciones de ortología y métrica de la lengua castellana (1835), al que le seguirá más tarde la Gramática de la lengua latina (1838).

7 Iván Jaksic sostiene que "probablemente se trata de Juan Alemparte Uribe (1825-1895), quien, por su edad en la década de 1840, debió ser alumno de Bello en la época en 
nombre cobra relevancia, ya que a través del contenido de su Cuaderno es posible acceder a algunas de las materias filosóficas específicas enseñadas por Bello. Es más, el Cuaderno de Alemparte resulta ser un franco testimonio de los primeros esbozos conceptuales relativos a filosofía vertidos por el profesor caraqueño en sus lecciones; esbozos que alcanzarán una forma más definida al hacerse públicos en El Crepúsculo ${ }^{8}$. En otras palabras, el Cuaderno de Alemparte es un documento histórico que, bajo cierto respecto, da cuenta de la génesis del pensamiento filosófico que Bello expresará luego en sus artículos aparecidos en El Crepúsculo; artículos que -como ya se adelantó- constituirán la base inicial del libro Filosofía del entendimiento.

El Cuaderno de Alemparte consiste en una transcripción directa de parte de las clases de filosofía dictadas por Bello en su domicilio. Su data oscila entre los años 1840 y 1843. El Cuaderno tiene una extensión de 20 carillas y trata mayormente sobre las percepciones. Lo que está en existencia en el Archivo Nacional Histórico (ANH) de Santiago de Chile corresponde a una copia más tardía del escrito original, quizás fechable entre los años 1860 y 1865 , dados el papel y la tinta utilizada.

A continuación, se presenta el documento íntegro. Solo se han modificado los subrayados en la fuente por la letra cursiva. La gramática castellana se actualizó con el fin de hacerlo legible, por ejemplo, se cambió la letra $j$ por la $g$; y la $i$ latina por la $y$. Adicionalmente, a pie de página, se han añadido notas explicativas, la mayoría de las veces para evidenciar su relación ya sea con el periódico El Crepúsculo o con el libro Filosofía del entendimiento.

que este trabajaba activamente en su Filosofía” (Rebeldes 68-9). Cabe señalar que Juan Alemparte Uribe fue un liberal que destacó en la revolución de 1851 como integrante del Cabildo de Concepción, ciudad de donde era oriundo, y por ser el redactor (1846) del diario local El Eco Nacional, que alcanzó los ocho números (Boletín del Sur 12).

8 Esto en contra de lo que considera Iván Jaksic (Orígenes 53-68), a saber, que los artículos de Bello publicados en El Crepúsculo representan la primera evidencia del plan de su obra de 1881, Filosofía del entendimiento. 


\section{CUADERNO DE JUAN ALEMPARTE}

\section{Transcripción}

Fondo Antiguo ANH, vol. 95, pieza 15, ff. 148r-167v.

[148r] Cuaderno de Filosofía. Dictado por Don Andrés Bello para el uso de Juan Alemparte.

\section{[F. I49R] Elementos de Filosofía9}

La filosofía, que más propiamente pudiera llamarse psicología, es la ciencia del alma humana.

Se divide en dos partes. La $1^{\text {a }}$ es la filosofía intelectual, llamada por algunos ideología ${ }^{10}$, que trata de las facultades y operaciones que sirven al alma para el conocimiento de sí misma y de los demás objetos. El conjunto de estas facultades y operaciones es lo que llamamos inteligencia

$9 \quad$ Los contenidos tratados en el Cuaderno de Juan Alemparte se corresponden con la entrega de los primeros siete números de El Crepúsculo, fechados de junio a noviembre de 1843, con la sola excepción del número cinco, dedicado especialmente a las fiestas patrias y publicado el día 18 de septiembre.

10 Con dicha denominación, se hace evidente la influencia de la obra Elementos de ideología, del filósofo francés Destutt de Tracy (1754-1836) en Bello y su interés por los problemas educativos. La denominación desaparece, sin embargo, en $F d E$, donde se hablará de psicología mental o intelectual. 
y entendimiento. La segunda es la ética o filosofía moral ${ }^{11}$, cuyo objeto es darnos a conocer las inclinaciones, deseos, pasiones y hábitos, cuyo conjunto constituye la voluntad.

La ideología aplicada a la buena dirección de las facultades intelectuales, encaminándolas al conocimiento de la verdad se llama lógica ${ }^{12}$, y la ética aplicada a la dirección de nuestras inclinaciones y deseos encaminándolos a nuestra felicidad presente y venidera se denomina derecho natural ${ }^{13}$. //

\section{[F. I 49V] Parte ía Ideología}

\section{Capítulo io De las percepciones en General ${ }^{\text {I4 }}$}

La primera de las operaciones del entendimiento es la percepción.

La percepción es un acto del alma, que experimentando una afección conoce por medio de ella el objeto que actualmente la produce. Es de dos maneras: intuitiva y sensitiva.

En la percepción intuitiva la afección del alma y el objeto se identifican. Por percepciones intuitivas conoce el alma sus juicios, imaginaciones, deseos, etc. La percepción intuitiva se llama de un modo más breve intuición o conciencia; aunque este segundo nombre suele aplicarse más a la facultad que al acto.

11 En FdE se distingue también estos conceptos (2). Allí Bello explica que la filosofía, en cuanto tiene por objeto conocer las facultades y actos de la voluntad, se llama psicología moral; y, en cuanto da reglas para la acertada dirección de los actos voluntarios, se denomina ética. Ambas dimensiones componen la filosofía moral.

12 En $F d E$ (2) el sabio venezolano explica que la filosofía, en cuanto da reglas para la acertada dirección de las facultades y operaciones del entendimiento, se denomina lógica. Esta última, junto con la psicología mental, conforman la filosofía del entendimiento.

13 Los contenidos desarrollados brevemente en esta sección son explicados con mayores detalles en la introducción de $F d E$ (1881). No obstante, como se ha indicado, allí ya no se hablará de ideología ni tampoco de derecho natural.

14 Las materias tratadas en esta sección se corresponden con las del homónimo artículo $1^{\circ}$ del primer número de El Crepúsculo $(1,4-10)$ y con las del capítulo 1 (De la percepción) de $F d E$ (6-20). 
En la percepción sensitiva el medio es una sensación y el objeto una cualidad corpórea. Conocemos v. g., la fatiga que es una cualidad del cuerpo animado, mediante aquella sensación penosa, que experimentamos a consecuencia de un largo ejercicio de los miembros. //

[f. 150r] Las sensitivas ${ }^{15}$

Las percepciones sensitivas son internas o externas. Se llaman internas cuando la cualidad percibida es una modificación orgánica del cuerpo animado, a la cual corresponde inmediatamente una sensación en el alma en virtud de las relaciones establecidas por el autor de la naturaleza entre ella y el cuerpo. Por percepciones sensitivas internas, conocemos la fatiga, el hambre, la sed, el sueño, los esfuerzos con que nos movemos, la opresión o angustia producida por un pesar en los órganos de la respiración, el asco o náusea que la vista o recuerdo de ciertos objetos excita.

Percepciones sensitivas externas son aquellas en que el alma conoce una cualidad corpórea, que produce en el cuerpo animado una impresión o modificación orgánica a la cual corresponde una sensación del alma. Conocemos v. g. que la superficie de un cuerpo es áspera o lisa, porque tocándolo se produce en la mano cierta impresión que transmitida al alma, excita en ella una sensación particular, por cuyo medio conoce el alma aquella cualidad del cuerpo tocado.

En la percepción sensitiva interna hay una afección orgánica que es su causa próxima, y es al mismo tiempo el objeto percibido. En la percepción sensitiva externa hay dos causas sucesivas, la cualidad corpórea que impresiona un // [f. 150v] órgano y la afección orgánica que se sigue la sensación. La causa remota es el objeto percibido.

15 Esta subdivisión de las materias no se halla en las entregas de El Crepúsculo (1843) ni en $F d E$ (1881). Sin embargo, los contenidos correspondientes se desarrollan más extensamente en las páginas 12-20 de esta última obra. Allí, se habla de impresión orgánica y se explica con mayores detalles las diferencias generales entre las percepciones sensitivas internas y externas, cuyo estudio más completo se desarrolla en los capítulos III y IV. 
En las percepciones sensitivas tanto internas como externas, lo que percibe el alma verdaderamente es la sensación. Las cualidades corpóreas no las percibe de un modo directo, no hace más que representárselas por medio de las sensaciones, que mediata o inmediatamente producen.

Nótese que la palabra percepción significa unas veces la facultad y otras el acto. Las facultades especiales de percepción sensitiva se llaman sentidos; tales son la vista, el oído.

Casi todas las percepciones sensitivas externas se reducen a las de los cinco sentidos que llamamos vista, oído, olfato, gusto, tacto, de que vamos a tratar en el capítulo siguiente.

La facultad de percibir los esfuerzos con que se produce el movimiento voluntario es un verdadero sentido interno que llamaremos sentido de esfuerzo. Las facultades especiales de la percepción sensitiva externa son innumerables. //

\section{[F. i 5 I ] Capítulo $2^{\circ}$ De las percepciones sensitivas EXTERNAS ${ }^{16}$}

En toda percepción sensitiva externa hay cinco cosas que notar: $1^{\text {a }}$ la acción del objeto sobre el órgano. $2^{\mathrm{a}}$ la impresión que se verifica en el órgano y que se transmite por los nervios hasta el cerebro. $3^{a}$ la sensación que se produce instantáneamente en el alma. $4^{\mathrm{a}}$ la percepción intuitiva de la sensación. $5^{\mathrm{a}} \mathrm{el}$ juicio que el alma forma refiriendo la sensación al objeto y representándose por medio de ella una cualidad particular del objeto. De estas cinco cosas las tres últimas pertenecen al alma.

Comparando entre sí las percepciones sensitivas externas hallamos en ella una diferencia notable. Las percepciones del tacto por ejemplo nos dan aviso de la dureza o blandura, suavidad o aspereza de los cuerpos que tocan inmediatamente la superficie del nuestro; al paso que por medio de la vista

16 Estos contenidos se corresponden con el artículo tercero, desarrollado en los números tres y cuatro de El Crepúsculo (3, 115-23; 4, 147-57) y con los del capítulo III de FdE $(30-45)$. 
percibimos colores, magnitudes y formas que se hallan a veces a grandísima distancia de nuestros ojos. Distinguimos estas dos especies de percepciones llamando a la primera plesioscópicas, porque nos dan a conocer cualidades de objetos que obran inmediatamente sobre los órganos, y a las segundas aposcópicas por una razón contraria. Las percepciones del tacto y // [f. $151 \mathrm{v}$ ] del gusto son plesioscópicas; las de la vista, oído y olfato, aposcópicas.

Sabido es que las sensaciones aposcópicas son producidas no menos que las otras por causas corpóreas que obran sobre los órganos inmediatamente. Si vemos un cuerpo lejano es porque rayos de luz que vienen de su superficie impresionan nuestros ojos. Si oímos una campana que suena tal vez a una legua de distancia es porque las vibraciones comunicadas por ella al aire afectan inmediatamente nuestros oídos. Si olemos una rosa que dista de nosotros dos o tres varas es porque los efluvios que ella despide vienen a herir nuestra nariz. ¿En qué consiste pues, que por medio de las afecciones de la vista, oído y olfato no nos parece percibir las cualidades de los cuerpos, que inmediatamente impresionan nuestros órganos, sino de cuerpos situados a veces a considerable distancia de nosotros? Esto es lo que vamos a explicar.

Como el tacto y la vista son los más importantes de los cinco sentidos, referimos a ellos las noticias que nos vienen de los otros. No tanto de que cierta afección del olfato acompańaba constantemente a ciertas afecciones de la vista y el // [f. 152r] tacto, por medio de las cuales percibíamos cierto color, figura y magnitud nos fue permitido asociar aquellas con estas y referirlas todas a una misma causa. Atribuimos, pues, a aquel cuerpo dotado de tal color, figura y magnitud una cualidad más, la de afectar de un modo particular el olfato. De la misma manera viendo y tocando un cuerpo que herido por otro producía constantemente una afección particular del oído, identificamos la causa de esta afección con la causa de las afecciones visuales y táctiles que la naturaleza asociaba con ella. Atribuimos, pues, a cierto cuerpo dotado de ciertas cualidades, de que nos informaban el tacto y la vista otra cualidad más, la de producir en ciertas circunstancias aquella afección del oído.

Nuestro entendimiento obedece a esta ley: si una sensación es producida por una serie de causas remotas, A, B, de las cuales A obra en 
B y B en el órgano, y si B no es de naturaleza que pueda afectar la vista o el tacto, pero A lo es, la afección del alma producida por B no parecerá venir inmediatamente de $\mathrm{A}$, esto es, percibiremos por medio de ella una cualidad de A.

La sensación en las percepciones aposcópicas del oído y el olfato es un signo, por el valor que la experiencia nos enseńó a dar // [f. 152v] a este signo, los sonidos y olores fueron para nosotros caracteres de los objetos que veíamos y tratábamos; y esta referencia objetiva se hizo tan familiar y se unió tan íntimamente con la sensación que llegaron ambas a perecernos una misma cosa.

Estos dos elementos, sensación y referencia objetiva, son verdaderas partes constituyentes de la percepción aposcópica, y aún de toda percepción sensitiva. Sin la $1^{a}$ nada habría; sin la segunda el alma no experimentaría más que modificaciones absolutas, que solo contemplaría su propio ser y no se representaría jamás las cualidades y acciones de una causa distinta de ella ${ }^{17}$.

Pero además de estos elementos constitutivos suelen haber en las percepciones sensitivas ciertos juicios secundarios, que verdaderamente no son partes de ella y que sin embargo nos parece a primera vista pertenecerles.

Contraigámonos al oído y al olfato. Después que aprendemos por la observación y el raciocinio a referir las sensaciones auditivas u olfativas a cuerpos distantes que en virtud de esta referencia // [f. 153r] llamamos sonoros u olorosos, sucedió a menudo que a las percepciones auditivas $\mathrm{u}$ olfáctiles acompañaban ciertos juicios más o menos vagos de la distancia o situación de los cuerpos sonoros u olorosos que los producían, y que no se hallaban actualmente al alcance de la vista ni del tacto. Inferimos por ejemplo de lo más o menos intenso de la sensación auditiva la distancia del cuerpo sonoro y aprendemos también a distinguir, mediante algunas otras modificaciones de la sensación, si el cuerpo sonoro estaba delante o detrás, a la derecha o a la izquierda, en una palabra, su situación respecto de nosotros. Enseñados a estimar las distancias y situaciones por el tacto y

$17 \quad$ Hasta este punto las materias expuestas coinciden, con leves modificaciones de redacción, con los contenidos del tercer número de El Crepúsculo $(3,118-21)$ y la primera sección del capítulo de $F d E(30-5)$. 
la vista, encontramos luego, observando relaciones constantes entre ciertos modos particulares de las sensaciones auditivas y olfáctiles, y ciertas distancias y situaciones, de lo que resultó que aun privados de la asistencia de la vista y el tacto pudimos por medio de las unas estimar hasta cierto punto las otras. De esta manera las sensaciones del oído y del olfato se hicieron signos de cualidades visuales y táctiles que estos sentidos no pueden percibir por sí mismos.

Debemos pues distinguir en las sensaciones aposcópicas del oído y del olfato // [f. 153v] dos especies de juicios: unos constituyen la referencia objetiva, esencial y primaria, y por medio de ellos nos representamos en los cuerpos visuales o táctiles cualidades rigurosamente auditivas u olfáctiles, de que la vista y el tacto no habrían podido jamás darnos la menor idea, mientras que por medio de los otros nos representamos cualidades visuales o táctiles de manera que las percepciones del oído y del olfato se hacen con este auxilio significativas y admiradoras de las percepciones de la vista y del tacto. A los primeros los llamamos juicios primarios, y a los segundos, secundarios $^{18}$.

Pasemos a la vista ${ }^{19}$. La percepción del color es producida por un fluido tenuísimo que media entre los objetos y los ojos a los cuales impresiona de diversos modos según las modificaciones que recibe de los objetos. Sin embargo, no referimos a este fluido, es decir a la luz, las sensaciones visuales. Nos representamos por medio de ellas cualidades o caracteres no de la luz, sino de los cuerpos distantes que la emiten. La razón de esta referencia objetiva es obvia. Entre los objetos // [f. 154r] táctiles y las modificaciones de la luz hay conexiones constantes, las hay luego entre las modificaciones de la luz y las del órgano de la vista, y luego entre estas modificaciones orgánicas y las sensaciones visuales. Las estaciones intermedias de la cadena

18 Las materias tratadas hasta este punto se corresponden con las del artículo $3^{\circ}$, en el tercer número de El Crepúsculo (3, 115-23), y con la segunda sección del capítulo III de $F d E$ (36-8). No obstante, en esta última obra ya no se habla de juicios primarios y secundarios, sino de percepciones primarias y percepciones secundarias, accesorias o sugeridas ( FdE 36-7).

19 El análisis de la vista que sigue se corresponde con los contenidos tratados en la segunda parte del artículo 3ㅇ, expuesto en el cuarto número de El Crepúsculo (4, 147-57). 
se hallaban fuera de nuestros alcances, pero observadas las correspondencias constantes establecidas por la naturaleza entre las varias sensaciones visuales y los varios objetos táctiles colocados en el espacio alrededor de nosotros, era natural y era necesario que las unas se nos hicieran representaciones o signos necesarios de las otras y que nos pareciese percibir en las afecciones visuales cualidades de los objetos táctiles. A estas cualidades dimos el nombre de colores.

Podemos, pues, expresar de un modo más general aquella ley del entendimiento que dedujimos poco hace de las percepciones del oído y del olfato, si una sensación es producida por una serie de causas remotas A, B, de las cuales, A obra en B, y B en el órgano. Si B no es perceptible al tacto, pero $\mathrm{A}$ lo es, la afección producida por $\mathrm{B}$ nos parecerá inmediatamente de A, esto es percibida por medio de ella una cualidad de A. // [f. 154v].

La percepción aposcópica de los colores es peculiar de la vista, y los cuerpos a que los atribuimos se llaman por eso visibles. Pero si por medio de este sentido supiésemos solo que tal o cual cuerpo existe a lo lejos, o si los avisos que nos da de la situación o distancia de los objetos fuesen tan vagos y oscuros como los del oído y el olfato, su sutilidad estaría reducida a bien poco. Lo que le da una inmensa importancia son sus juicios secundarios y la determinación y claridad de estos juicios.

Figurémonos el órgano de la vista como una superficie que está en contacto con una miniatura ${ }^{20}$ del universo externo formada por las extremidades de los rayos de luz que nos vienen inmediatamente de los objetos. Sabemos que el ojo es un instrumento destinado a producir esta miniatura y que la produce en efecto con una regularidad y precisión admirables. Llamemos situaciones, distancias, magnitudes y figuras visuales las que los objetos presentan en la miniatura; situaciones, distancias, magnitudes y figuras táctiles las que descubriríamos, si privados de la vista // f. 155r]

20 Este párrafo se encuentra reproducido idénticamente en El Crepúsculo (4, 151-52) y, con modificaciones mínimas de redacción, en la tercera sección del capítulo III de FdE (39-40). Sin embargo, en lugar de utilizar en esta última obra la noción "miniatura", emplea el concepto de "pintura ocular", el que explica luego con mayores detalles (FdE 40-4). 
nos dirigiésemos a tientas hacia los objetos y palpásemos su superficie. Es claro que los diferentes pormenores de la miniatura producirán diferencias correlativas en las sensaciones visuales, y como aquellos pormenores tienen relaciones constantes con las distancias, situaciones, magnitudes y figuras táctiles de los objetos visibles, no puede menos de haber iguales relaciones entre estas cualidades táctiles y las sensaciones visuales; de que se sigue que, instruidos de esta conexión por la experiencia, podemos colegir las unas de las otras y percibirlas en ellos. Debemos de este modo a la vista muchos juicios secundarios de cualidades que en realidad no pertenecen al dominio de este sentido sino del tacto, y de que el tacto no pudiera informarnos sino lenta y difícilmente o tal vez de ningún modo. ¿Cuánto tiempo no gastaríamos en estudiar a tientas los pormenores de la fachada de un vasto edificio de los cuales nos informa la vista en pocos momentos? ¿Y de qué modo llegaríamos a conocer sin ella la situación, distancia y dimensiones de aquellos cuerpos a que no nos es posible acercarnos?

Pasemos a las percepciones ple- // [f. 155v] sioscópicas ${ }^{21}$. Las del gusto acompañan tan inseparablemente las del tacto que no podemos menos de atribuir los sabores a las sustancias táctiles que impresionan el paladar y la lengua, órganos a un mismo tiempo de las percepciones de ambos sentidos.

El olfato nos da algunas veces percepciones plesioscópicas. En un laboratorio de química por ejemplo atribuimos ciertos olores a ciertas sustancias invisibles e impalpables que obran inmediatamente en el órgano. Conocida además la agencia de los efluvios en la olfacción, podemos referir a ellos en todos casos las afecciones del olfato. ¿Y quién nos quita hacer otro tanto en la audición respecto del medio que transmite el sonido y en la visión respecto de la luz? El que conoce el proceder de la naturaleza en la acción material de que nacen las afecciones de los sentidos aposcópicos se puede decir, con toda verdad, que tiene percepciones plesioscópicas de las sustancias que obrando inmediatamente sobre los órganos los afectan. // [f. 156r].

$21 \quad$ Las materias que siguen hasta el final de este capítulo son desarrolladas, con modificaciones mínimas de redacción, tanto en el cuarto número de El Crepúsculo (4, 156-7), como en la cuarta y última sección del capítulo de $F d E$ (44-5). 
La agencia de los gases, de los efluvios odoríferos, de las vibraciones aéreas sonoras y de los rayos luminosos no se perciben por el tacto ni por la vista, pero se deduce de raciocinios fundados en observaciones y experimentos que se resuelven en percepciones táctiles, o en percepciones de la vista, como representativa del tacto. Además, nos figuramos estas sustancias como agregados de moléculas o cuerpecillos que tienen cualidades táctiles y que solo por su extremada tenuidad se diferencian de los cuerpos que podemos ver o tocar. De aquí se sigue que el tacto es el sentido externo por excelencia, que todos los otros no hacen más que sobreponer una línea particular a los objetos táctiles o suplir los informes del tacto: y que el universo exterior es para nosotros un sistema de cosas, magnitudes, formas, distancias y situaciones verdadera o imaginariamente palpables.

El tacto, pues, si se me permite esta expresión, ha sido el instructor ${ }^{22}$ de los sentidos aposcópicos, pero lo vista ha sido el primer discípulo del tacto. Amaestrada por él, ha repetido las lecciones de este sentido a los otros. Y una vez que las percepciones aposcópicas se han perfeccionado por medio de los juicios // [f. 156v], secundarios que entran en ellas, nos han servido para suplir y adicionar en multitud de casos las percepciones del tacto, evitándonos la necesidad de consultarlo, y en esto consiste más particularmente la inmensa utilidad de la vista.

Debemos en último resultado a la experiencia del tacto los juicios primarios y secundarios que entran en las percepciones de los otros cuatro sentidos. ¿Pero quién ha dado al tacto su referencia objetiva? Esta es una cuestión que procuraremos resolver más adelante. Por ahora bástenos haber demostrado que las afecciones táctiles son la causa, el sujeto, la sustancia a que sobreponemos todas las otras para representarnos el universo exterior. //

22 Cabe señalar que en el párrafo afín de $F d E(45)$, se indica que el tacto es el maestro de los sentidos aposcópicos, y que la vista ha sido enseńada -y no amaestrada- por él. 


\section{[F. I 57R] Capítulo $3^{\circ}$ Percepciones sensitivas internas ${ }^{23}$}

Nuestro cuerpo (y consiguientemente los demás cuerpos animados a causa de la semejanza que concebimos entre aquel y estos) no nos es conocido solamente por el tacto y por los sentidos auxiliares del tacto. Las percepciones ya del bienestar o placer, ya de la incomodidad, desazón o dolor que atribuimos a varias partes de la máquina que animamos o a toda ella; v. g. las percepciones de sueńo, fatiga, hambre, nos representan modificaciones corpóreas muy diferentes de las que percibimos en los cuerpos inanimados. Las percepciones de los esfuerzos internos con que producimos los movimientos voluntarios; las percepciones de aquellos estados de movilidad o inercia, de vigor o debilidad, que acompañan a la alegría o tristeza, miedo, todas estas percepciones y otras cuyo catálogo sería largo y difícil, forman gran número de especies distintas que no pertenecen a ninguno de los cinco sentidos de que hablamos en el capítulo precedente. Ellas representan modificaciones propias del cuerpo animado, y los órganos son las partes mismas a que referimos más // [f. 157v] o menos distintamente las afecciones sensitivas, de manera que en ellas el órgano y el objeto se identifican. Si las percepciones de los cinco sentidos representan causas remotas, causas que obrando sobre nuestros órganos los impresionan, las percepciones de estos otros sentidos representan causas próximas, impresiones orgánicas. Aquellas se llaman por eso sentidos externos, y estos internos.

Descompónense las percepciones de los sentidos internos, como las de los otros, en sensación, intuición y referencia objetiva. La percepción del hambre, por ejemplo, se resuelve en la sensación producida en el alma a consecuencia de cierta modificación del estómago, en la intuición de esta sensación y en el juicio que refiere la sensación al estómago y se representa en ella un estado particular de este órgano.

23 Estos contenidos coinciden, con leves modificaciones, con los del artículo $4^{\circ}$ de $E l$ Crepúsculo $(6,223-37)$, y con el capítulo IV de FdE (46-61). Su principal diferencia es que en estas últimas obras se incluye el relato de un experimento realizado por el doctor Brown para apoyar la argumentación (El Crepúsculo 6, 228-9; FdE 51). 
Es evidente que el estado orgánico que produce inmediatamente la sensación, y la sensación por medio de la cual recibe el alma aviso del estado orgánico, son dos cosas enteramente distintas, siendo aquel un fenómeno corporal que nos representamos por medio de la sensación y este un fenómeno intelectual que el alma percibe intuitivamente en sí misma // [f. 158r]. Ignoramos por ejemplo qué mutaciones mecánicas y químicas se verifican en nuestra máquina cuando nos rendimos al sueño, pero distinguimos perfectamente la afección sensitiva que las acompańa y nuestro entendimiento se las representa por medio de ella.

Como toda sensación se puede referir a su órgano y producir de este modo una percepción sensitiva interna, es claro que las sensaciones con que nos representamos las cualidades de los cuerpos externos pueden servir al mismo tiempo para representarnos las impresiones orgánicas de que inmediatamente emanan. La sensación, por ejemplo, con que me represento el color de la nieve, puede servir al mismo tiempo para representarme la afección orgánica producida en los ojos por los rayos luminosos que refleja la nieve. La materia de las percepciones internas y externas, el signo espiritual de la impresión producida por la nieve en el órgano de la vista es uno mismo, pero la referencia objetiva es diversa. El objeto de la primera es la nieve bajo cierto color; el objeto de la segunda es el órgano de la vista bajo cierta impresión. Una misma sensación significa en nuestro entendimiento dos cosas, su causa próxima y su causa remota.

Hemos visto que podemos mirar la sensación como signo de una causa más o menos remota, como signo de una cualidad del fluido luminoso // [f. $158 \mathrm{v}]$ que afecta inmediatamente los ojos, o como signo de una cualidad del cuerpo que nos lo envía. Por consiguiente, cada sensación visual es para nosotros un signo triple, que nos representa, ya cualidades de los cuerpos distantes que vemos, ya cualidades del fluido por cuyo medio las vemos, ya modificaciones del órgano; dándonos en el primer caso una percepción externa aposcópica, en el segundo una percepción externa plesioscópica, y en el tercero una percepción interna. En todas tres, la sensación es una misma: pero la referencia es diversa. En todas las percepciones aposcópicas la sensación es un signo a que podemos dar tres significados diferentes. 
En las percepciones sensitivas internas que nos representan las impresiones orgánicas que acompañan al ejercicio de los cinco sentidos externos la causa remota nos es conocida por percepciones sensitivas externas. En otras percepciones sensitivas internas conocemos la causa remota por medio de una percepción intuitiva. Así sucede en el sentido de esfuerzo.

Esfuerzo es la modificación puramente orgánica que se produce en alguna parte de nuestro cuerpo, a consecuencia // [f. 159r] de querer el alma ejecutar algún movimiento con ella. El esfuerzo es propio del cuerpo, como la volición lo es del alma; y consiste en una contracción muscular. Percibimos y distinguimos unos de otros los modos de ser materiales que llamamos esfuerzos, en cuanto percibimos y distinguimos unas de otras las sensaciones producidas por ellos. El esfuerzo que mueve un párpado produce en el alma diferentes afecciones que el esfuerzo que mueve los labios o la lengua. La serie de esfuerzos necesarios para pasar la mano sobre una superficie esférica produce una serie de sensaciones muy diversas de la que sería producida para pasar la mano sobre una superficie prismática o cúbica. Por medio de la conciencia percibimos esta variedad de sensaciones, y cuando el tacto y la vista nos hubieron dado conocimiento de nuestra propia forma corpórea, y nos hicieron formar conexiones entre cada afección del sentido de esfuerzo y cada movimiento visible o tangible de una parte de nuestro cuerpo, no nos fue difícil referir las sensaciones de esta especie a sus causas próximas, es decir, a los órganos de los respectivos movimientos voluntarios.

Es claro que la facultad que tenemos de percibir los esfuerzos que la voluntad // [f. 159v] produce en nuestro cuerpo es un verdadero sentido, esto es una facultad que percibe cualidades o modificaciones corpóreas por medio de sensaciones.

La causa remota de las afecciones sensitivas que producen percepciones externas es una sustancia corpórea, la de las afecciones del sentido interno de esfuerzo es el alma misma. Percibimos la primera por los sentidos externos y la segunda por la conciencia.

Sucede otro tanto en muchas otras percepciones sensitivas internas.

Cuando las percepciones, recuerdos, fantasías, producen modificaciones orgánicas de que por una especie de reacción resultan al alma sensaciones 
agradables o dolorosas, se forman en ella estados complejos que suelen llamarse emociones, sentimientos, afectos, pasiones, como la alegría, tristeza, ira, cariño, admiración, lástima, vergüenza, horror y otros varios. Estos estados se componen de dos elementos espirituales: la percepción, recuerdo o fantasía del objeto que excita alguno de estos afectos y la percepción sensitiva interna de una modificación orgánica agradable o penosa. Por ejemplo: percibimos un objeto lastimoso en virtud de ciertas leyes de correspondencia // [f. 160r] entre el alma y el cuerpo; esta percepción excita en el pecho y la garganta modificaciones particulares que si son bastante intensas hacen derramar lágrimas; y estas modificaciones orgánicas excitan a su vez en el entendimiento percepciones internas de ellas. Los modos intelectuales ejercen, no sabemos cómo, cierto influjo sobre los órganos: impresionados estos obran a su vez sobre el entendimiento produciendo en él sensaciones varias; y estas sensaciones nos representan sus causas próximas, que son las modificaciones orgánicas, al paso que las causas remotas, es decir aquellos modos intelectuales, solo nos son conocidos por la conciencia.

Hay otro género de percepciones sensitivas internas, cuya causa remota, esto es, el estímulo presente de que emanan las modificaciones orgánicas, nos es enteramente desconocido. El hambre sucede a la inedia, la fatiga al ejercicio violento, el sueño al uso de bebidas narcóticas, etc.; pero no percibimos en estos casos una agencia de nuestro yo ni referimos la sensación a causa alguna que esté impresionando actualmente los órganos, como lo hacen las causas remotas en las percepciones sensitivas internas. // [f. 160v]

Hay pues tres especies de sensaciones sensitivas internas: unas en que la causa remota es conocida por medio de una sensación que al mismo tiempo significa la impresión orgánica y la causa remota; otras en que la causa remota es un acto de la voluntad o un estado del entendimiento, conocido por la conciencia; y otras en que la causa remota que despierta actualmente la impresión orgánica nos es actualmente desconocida. 
La percepción del calor ${ }^{24}$ es plesioscópica cuando percibimos por el contacto inmediato que una sustancia sólida o líquida o el ambiente que nos circuye está caliente; es aposcópica cuando atribuimos el calor a un cuerpo que está algo distante de nosotros, v. g., el fuego del hogar, y es interna, cuando en la fiebre o después de un ejercicio violento sentimos calor.

La percepción del calor se suele reducir al tacto porque frecuentemente acompaña a las percepciones de este sentido, pero no sucede así siempre, y aun cuando así suceda, la cualidad representada por la sensación de calor no es propiamente tangible, como no lo son los sabores, sin embargo, de que las afecciones del gusto están inseparablemente unidas con las del tacto. Las percepciones // [f. 161r] del calor pertenecen verdaderamente a un sentido particular, cuyos órganos son aún más extensos que los del tacto, pues no solo abrazan toda la superficie de nuestro cuerpo, sino también nuestras partes internas.

Como los diferentes grados de calor y de frío forman una serie continua, forman también una serie de sensaciones correspondientes, y podemos reducirlas todas a un mismo sentido.

Nos es necesario suponer instintos particulares, en virtud de los cuales referimos las sensaciones a sus órganos ${ }^{25}$. Lo $1^{\circ}$ porque mediante el tacto y la vista pudimos referir con facilidad las sensaciones táctiles a los suyos. Lo $2^{\circ}$ porque el tacto y la vista han podido darnos a conocer desde muy temprano la conexión entre muchas otras especies de sensaciones y los órganos respectivos. Lo $3^{\circ}$ porque habiendo aprendido a conocer en gran número de casos por el concurso de las sensaciones internas con las externas la situación de los órganos, no era difícil que adquiriéramos conocimientos más o menos exactos de la misma especie en muchos otros, por medio de proporciones y analogías que se nos hiciesen poco a poco habituales.

24 Los tres párrafos que siguen, que se refieren a la percepción del calor, son tratados en la segunda sección del capítulo IV de FdE (53-4). En El Crepúsculo, en cambio, son estudiados dentro del mismo artículo, sin presentar subdivisión alguna (6, 233-4).

25 Los contenidos tratados desde aquí hasta el final del capítulo son desarrollados, con mayor extensión, en la tercera sección del capítulo aludido de $F d E$ (55-7). En El Crepúsculo, en cambio, las materias se estudian en el cuerpo del mismo capítulo y no en una sección especial $(6,234-7)$. 
El juicio que refiere cada // [f. 161v] sensación a un órgano tangible más o menos determinado, se hace tan fácil y rápidamente, que el alma nos parece hallarse presente al órgano y casi identificarse con él. Y produciéndose en nosotros a cada paso multitud de percepciones internas, nos figuramos que todas las partes de nuestra máquina corpórea gozan continua y simultáneamente de la presencia del yo, y que la existencia de que tenemos intuición las penetra y vivifica todas.

Este aprendizaje de los sentidos por el tacto presupone en las percepciones táctiles una referencia objetiva, que no puede resolverse en otra alguna, y es la base de todas las otras; es, a saber, aquella mediante la cual nos representamos los objetos percibidos por este sentido como causas distintas e independientes del yo. De qué manera hayamos llegado a formar este juicio primitivo, origen y fundamento de todas las referencias objetivas es una cuestión difícil de que trataremos en otra parte //.

\section{[F. I62R] Capítulo $3^{\circ}$ De las Percepciones intuitivas ${ }^{26}$}

Conciencia es la facultad con que el alma percibe sus propias afecciones y operaciones. ¿Quién no percibe en sí mismo las sensaciones, los recuerdos, las imaginaciones, la aversión o el deseo, la aflicción o el contento? Todas las percepciones de esta especie pertenecen a la conciencia. La conciencia hace todavía más, pues se percibe a sí misma. Sin esta facultad la psicología o ciencia del alma no existiría.

Solemos dar a la palabra conciencia un significado mucho menos extenso entendiendo por ella el testimonio que el alma se da a sí misma

26 Estos contenidos coinciden con los estudiados en el artículo 2o de El Crepúsculo (2, 51-6), y en el capítulo II de FdE (21-9), cuyo título en ambas obras es "De las percepciones intuitivas y de la conciencia”. En ambos escritos, Andrés Bello se explaya extensamente acerca de las afecciones y modificaciones del alma. Para ello, recurre, por ejemplo, a las enseñanzas del doctor Tomas Brown (Lectures on the Philosophy of the Human Mind, 1820), sucesor de Dugald Stewart en una de las cátedras de filosofía de la Universidad de Edimburgo, de quien, sin embargo, el sabio venezolano toma distancia (El Crepúsculo 2, 52-3, 56; FdE 22, 25). 
de la bondad o maldad de sus actos, o la facultad que tenemos de percibir en ella estas cualidades morales. La conciencia en este sentido no es la facultad perceptiva que contempla todos los modos espirituales, sino una facultad especial que tiene por objeto averiguar la relación de semejanza o diferencia entre nuestros actos voluntarios y las reglas naturales o positivas a que debemos conformarlos.

La conciencia, además, en su significado psicológico, denota unas veces la facultad y otras el acto. Yo doy a los actos, cuando creo conveniente distinguirlos de la facultad, el nombre de percepciones intuitivas o intuiciones. // [f. 162v]

Las percepciones sensitivas internas, sobre las que tratamos en el capítulo precedente, no tienen nada que ver con las intuiciones de la conciencia; aquellas representan por medio de varias afecciones del alma los varios estados y modificaciones de nuestro cuerpo; estas contemplan inmediata y directamente las afecciones del alma.

La conciencia es la reguladora necesaria de todos los actos intelectuales. Ella es un elemento indispensable de las percepciones sensitivas, pues, para referir una sensación a su causa y representarnos esta con aquella, que es lo que constituye la percepción sensitiva, es con esta que primero percibimos en nosotros mismos la sensación.

Así como las sensaciones aposcópicas pasan a plesioscópicas cuando por medio de las afecciones sensitivas queremos representarnos cualidades de las causas remotas que obran inmediatamente sobre los órganos; y las percepciones externas pasan a internas cuando por medio de dichas afecciones representamos no cualidades de causas remotas sino modificaciones orgánicas, así también si suponemos un estado del alma en que por falta de ciertas observaciones o instintos particulares que nos hagan referir las sensaciones a sus causas próximas o remotas, seamos incapaces de representarnos por medio de las sensaciones, los modos // [f. 163r] orgánicos y los influjos de los cuerpos extrańos, las percepciones que entonces tendrá el alma a consecuencia de las sensaciones serán puramente intuitivas, porque una sensación de un modo espiritual, como otro cualquiera, y la contemplación 
de un modo espiritual es una percepción puramente intuitiva, mientras no lo hacemos signo de una causa distinta del alma.

Lo que hay verdaderamente perceptible en las percepciones sensitivas es la intuición o el acto de la conciencia por el cual percibe el alma la sensación. El alma no percibe verdaderamente, sino a sí misma: los cuerpos en rigor no los percibe. Percibe, en verdad, efectos de las acciones corpóreas porque percibe por la conciencia las sensaciones; pero el representarse en estos efectos unas causas que no conoce de otra manera, no es propiamente percibirlas. Este, sin embargo, por imperfecto que nos parezca es el único medio que tenemos de conocer, comparar y distinguir las cualidades corpóreas. Inútilmente nos empeñaríamos en desnudarlas del atavío de nuestros propios modos de ser, para concebir lo que son en sí mismas. "En vano (dice un discípulo de Kant) quisiera el alma echar un puente sobre el abismo que la separa de los objetos. Trabajando en descartar sus percepciones representativas se consumiría en impotentes esfuerzos, semejante a la paloma que murmurase de la resistencia del elemento que la sostiene creyendo // [f. 163v] volar mejor en el vacío".

Antes de pasar más adelante haremos algunas observaciones sobre la propiedad de varias palabras relativas a la facultad de percibir ${ }^{27}$.

Sentir en el lenguaje vulgar significa a menudo lo mismo que percibir sensitivamente. Así se dice sentir ruido, pasos, sueño, fatiga, hambre, sed. Otras veces aplicamos esta palabra a las afecciones dolorosas evitadas por causas morales, como cuando se dice sentimos las ofensas o los accidentes desgraciados. Otras veces experimentamos sensaciones. En el lenguaje técnico que me propongo usar, sentir es una cosa absoluta, es experimentar sensaciones; percibir, supone siempre un objeto. Es probable que el hombre siente desde los primeros momentos de su existencia, pero careciendo al principio de la facultad de referir lo que sentía a causas corpóreas actuales, no se puede decir que por medio de sus sensaciones percibiese entonces sensitivamente. No por lo que he dicho se entienda que me impongo la ley de usar siempre

Las definiciones que siguen se corresponden con las secciones de El Crepúsculo (7, 261-3) y $F d E$ (59-61), en las que se ofrecen algunas observaciones sobre el uso vulgar o trópico de ciertas palabras. 
la palabra sentir en su significado técnico, pues no me parece necesario abandonar sus otras acepciones vulgares cuando no producen confusión.

Sensible tiene dos acepciones: // [f. 164r] una activa y otra pasiva. En la primera significa lo que es capaz de experimentar sensaciones; en la segunda lo que puede excitarlas. Sensibilidad significa solo la capacidad de experimentar sensaciones.

Sentido no tiene el significado absoluto de sentir. El sentido de la vista es la facultad de percibir por medio de sensaciones visuales; el sentido del tacto, la facultad de percibir por medio de sensaciones táctiles; y otro tanto se aplica a los demás sentidos externos e internos. Aunque estos últimos carecen de nombres específicos en la lengua común, no veo inconveniente en decir el sentido del hambre, del sueńo, de los esfuerzos, etc. //

\section{[F. I64V] Capítulo $4^{\circ}$ De Las Percepciones Relativas ${ }^{28}$}

Podemos asimismo dividir las percepciones en absolutas y relativas, según son absolutas o relativas las cualidades contempladas por ellas. Absolutas son aquellas que se perciben sin necesidad de comparar un objeto con otro: v. g. el color. Relativas por el contrario las que solo pueden percibirse comparando distintos objetos: v. g. la semejanza.

La cualidad relativa o la relación no pertenece a ninguno de los objetos que se comparan, considerado en sí mismo, ni consiste en las cualidades que se comparan. Ella pertenece de tal modo a los objetos comparados que no es posible percibirla en todo ni en parte si el alma no los ve, por decirlo así, el uno al lado del otro. No pudiéramos por ejemplo concebir total ni parcialmente la semejanza entre el color de la azucena y el de la nieve, si no percibiésemos o recordásemos a un tiempo ambos colores; ni la sucesión entre el relámpago y el trueno, si la memoria del relámpago y la percepción

$28 \quad$ Estos contenidos se corresponden con la tercera parte del capítulo quinto de $E l$ Crepúsculo (Del juicio y de la relación, 7, 264-70) y con el capítulo V de FdE (62-9). En ambas obras, por cierto, se presenta una redacción mucho más elaborada de las materias. 
o la memoria del trueno // [f. 165r] no existieran a un mismo tiempo en el alma. Representándonos simultáneamente ambas cosas concebimos entre ellas las relaciones particulares que significamos diciendo que son semejantes, o que una es antes y otra después.

Entiéndese regularmente por comparación cierto conato voluntario con que atendemos a dos o más objetos a un tiempo para percibir sus relaciones. Aquí prescindimos de esta intervención de la voluntad. En la mayor parte de los casos las percepciones relativas nacen en nuestro espíritu a consecuencia de las simultaneidades fortuitas de dos o más afecciones mentales, sin el menor designio y esfuerzo nuestro y a nuestro pesar muchas veces.

Percibimos relaciones ya entre las cualidades corpóreas o causas remotas de las sensaciones, ya entre los varios modos y actos del alma. Podemos, por ejemplo, percibir que dos colores o dos dolores se asemejan, o que un deseo es más intenso que otro, o que a una sensación se sucede un deseo.

Es claro que las relaciones entre las causas próximas o remotas que afectan la facultad de sentir no pueden concebirse directa, sino solo representativamente. Si nos parece semejante el color de un cuerpo al color de otro cuerpo es porque nos parecen asemejarse las sensaciones visuales excitadas por ambos // [f. 165v]. Si nos parece que dos o más objetos tangibles se nos presentan en cierto orden sucesivo es porque se excitan en nosotros según este orden las sensaciones táctiles con que los percibimos. ¿Cómo juzga un enfermo que el dolor que siente hoy es más intenso que el dolor que sintió ayer? Porque compara una afección que existe actualmente en el alma con otra afección que existió en ella, que la memoria la representa; y porque percibe entre los dos aquella relación particular que significamos diciendo que una cosa es más y otra menos. En suma, no percibimos relación alguna, sino entre los modos y actos del alma. De las que existen entre las cualidades corpóreas y entre las afecciones orgánicas, no tenemos ni podemos tener conocimiento alguno directo, porque no percibimos las cualidades corpóreas y las afecciones orgánicas como son en sí, sino como nuestras sensaciones las representan. Todo lo que puede hacer nuestro entendimiento es figurarse las relaciones materiales, por medio de aquellas que percibe directamente comparando unas sensaciones con otras. 
A la manera que en la percepción de una cualidad absoluta corpórea // [f. 166r] tenemos intuición o conciencia de la sensación producida por ella y referimos esta sensación a una causa distinta del alma, así también cuando percibimos relación entre dos cualidades corpóreas percibimos intuitivamente la relación que existe entre las sensaciones producidas por ella, y atribuimos la relación a ellas. Por consiguiente, la percepción de una relación entre dos modos del alma es una mera intuición, pero la percepción de una relación entre dos modos corpóreos consta de dos elementos: intuición de la relación entre los modos del alma, que representa estos modos corpóreos, y juicio que atribuye la relación a estos modos corpóreos.

No solo por medio de las percepciones actuales podemos conocer relaciones, sino también por medio de las percepciones recordadas o imaginadas.

Podemos percibir relaciones de relaciones. El juicio que formo comparando el color de la violeta con el de la lila me parece semejante al juicio que formo comparando el olor del clavel con el olor del clavo de especia: la relación entre aquellos colores me parece semejante a la relación entre estos olores; percibo en suma semejanza entre dos semejanzas. // [f. 166v] Podemos del mismo modo concebir semejanza entre dos relaciones de sucesión, o sucesión entre dos relaciones de semejanza. Las relaciones son pues de diversos órdenes: unas primarias, que percibimos entre cualidades absolutas, y otras secundarias, que percibimos contemplando una relación o una cualidad relativa con otra de la misma especie.

Las cualidades tanto absolutas como relativas son simples o complejas. Si la percepción es simple la cualidad correspondiente nos lo parecerá también y por consiguiente lo será para nosotros, porque en nuestro entendimiento el ser de las cualidades y el de las percepciones que tenemos de ellas, se identifican. El olor de la rosa, por ejemplo, es una cualidad absoluta simple. El orden sucesivo entre una volición y el movimiento de un miembro es una cualidad relativa de la misma especie. Por el contrario, la cualidad que nos es conocida por dos o más percepciones diferentes es compleja.

Cuando tratamos de explicarnos a nosotros mismos alguna cosa o de darla a conocer a otros, contemplamos o hacemos contemplar sus varias 
partes y la resolvemos mentalmente en los elementos de que se compone. Pero // [f. 167r] el entendimiento no obra sobre los objetos mismos, sino sobre las percepciones que tiene de ellos. Las cualidades simples, las cualidades a cuyo conocimiento hemos llegado por percepciones simples no son, pues, susceptibles de definirse o de explicarse, ni podemos indicarlas sino indicando las respectivas percepciones. No podemos representarnos el color blanco o negro sino como la causa de aquella percepción particular de la vista que nos lo ha dado a conocer, ni pudiéramos darlo a conocer a otros, sino poniéndolos en situación de percibirlos. De la misma suerte las relaciones elementales, v.g., la de semejanza, o la de sucesión, sin embargo, de que las conocemos y distinguimos perfectamente, son inexplicables e indefinibles. ¿Quién no distingue la relación que expresamos diciendo que un sonido se parece a otro, de la que expresamos diciendo que un sonido se oyó después de otro? Y con todo eso es imposible definir o explicar qué es lo que constituye la semejanza o la sucesión de las cosas.

Resta otra diferencia a que me parece conveniente atender. Hay relaciones en virtud de las cuales damos a los objetos comparados una misma denominación; y relaciones en virtud de las cuales damos a los objetos comparados denominaciones de significado contrario. // [f. 167v]

A las primeras llamamos homólogas y a las segundas antílogas. La relación de semejanza, por ejemplo, es homóloga si A tiene semejanza con B. B la tiene forzosamente con A, y decimos indiferentemente de cualquiera de los dos que es semejante al otro, o decimos de ambos que son semejantes entre sí.

Pero la relación de causalidad en virtud de la cual concebimos que una cosa es causa de otra es antíloga; si A es causa de B, B es forzosamente efecto de A, denominaciones de significado no sólo diferente, sino contrario.

Las relaciones elementales en que se resuelven más frecuentemente las otras son la de semejanza o diferencia, la de más y menos, la de sucesión y la de identidad o distinción. Las complejas son de innumerables y diversas especies. // 


\section{Bibliografía}

Aravena Zamora, Abel. "Fuentes filosóficas para el estudio del aristotelismo en Chile colonial". Hipogrifo. Revista de Literatura y Cultura del Siglo de Oro, vol. 8, n. ${ }^{\circ}$ 2, 2020, pp. 307-25.

_. $\quad$ "La enseñanza de la filosofía natural en la última época colonial chilena: el Tratado acerca de los elementos y las instituciones de fisica de Manuel Antonio Talavera". Revista Española de Filosofía Medieval, vol. 26, n. ${ }^{\circ}$ 2, 2019, pp. 93-116.

_. "La Física contra Tomistas de Lorenzo Romo S. J.: apuntes sobre una controversia filosófica en el Chile del siglo XVIII”. Universum. Revista de Humanidades y Ciencias Sociales, vol. 33, n. ${ }^{\circ}$ 2, 2018, pp. 53-73.

- $\quad$ "Sobre unas conclusiones filosóficas defendidas en la Real Universidad de San Felipe (Santiago de Chile, 1807)". Revista Communitas, vol. 3, n. ${ }^{\circ}$ 6, 2019, pp. 220-43.

Amunátegui, Miguel Luis. Vida de don Andrés Bello. Santiago: Publicaciones Embajada de Venezuela, 1962.

Bello, Andrés. Boletín del Sur. Concepción: Imprenta del Correo del Sur, 1851.

_. $\quad$ El Crepúsculo. Santiago: Imprenta del Crepúsculo, 1843-1844.

_. Filosofía del entendimiento. Santiago: Imprenta de Pedro G. Ramírez, 1881.

Feliú, Guillermo. Estudios sobre Andrés Bello. Santiago: Fondo Andrés Bello, 1966.

Hanisch, Walter. Tres dimensiones del pensamiento de Bello: religión, filosofia, historia. Santiago: Pontificia Universidad Católica de Chile, 1965.

Jaksic, Iván. Andrés Bello: la pasión por el orden. Santiago: Editorial Universitaria, 2001.

_. "Orígenes del Filosofía del entendimiento: los aportes de Andrés Bello al periódico El Crepuisculo". Anales de Literatura Chilena, n. ${ }^{\circ} 13,2010$, pp. 5368.

_. Rebeldes académicos. La filosofía chilena desde la Independencia hasta 1989. Santiago: Ediciones Universidad Diego Portales, 1989.

Jobet, Julio César. Doctrina y praxis de los educadores representativos chilenos. Santiago: Editorial Andrés Bello, 1970. 
Lastarria, José Victorino. Recuerdos literarios. Santiago: Imprenta de la República de Jacinto Núñez, 1878.

Silva, Raúl. Don Andrés Bello 1781-1865. Santiago: Editorial Andrés Bello, 1970. 